\title{
Effects of Acute Tryptophan Depletion on Mood and Cortisol Release in First-degree Relatives of Type I and Type II Bipolar Patients and Healthy Matched Controls
}

\author{
S. Sobczak, Ph.D., A. Honig, M.D., Ph.D., N.A. Nicolson, Ph.D., and W.J. Riedel, Ph.D.
}

Biological vulnerability for bipolar disorders $(B D)$ in relatives of $B D$ patients has not as yet been established. Serotonergic vulnerability was studied, using acute tryptophan depletion (ATD), in healthy first-degree relatives of $B D$ patients and healthy controls. The effects of ATD on mood and cortisol release in 30 healthy adult, lifetime symptom free, unaffected first-degree relatives of $B D$ patients (Family History; FH) were compared with effects in 15 healthy matched controls in a placebocontrolled, double-blind, crossover design. During ATD and placebo, salivary cortisol response was also assessed during a stress-inducing speech task (SIST). First-degree relatives of type II BD patients (FH II) showed an elevation of mood, whereas control subjects and relatives of type $I B D$ patients (FH I) showed a lowering of mood after ATD. ATD was followed by a decrease in cortisol level in both $\mathrm{FH}$ subgroups, but not in the controls. The results suggest serotonergic vulnerability that affected mood in FH II subjects and cortisol release in both FH I and FH II subjects. [Neuropsychopharmacology 27:834-842, 2002] (C) 2002 American College of Neuropsychopharmacology. Published by Elsevier Science Inc
KEY WORDS: Bipolar disorder; Cortisol; Family history; Mood; Serotonin; Tryptophan depletion

In the pathophysiology of bipolar disorders (BD), several lines of evidence support the hypothesis of an underly-

From the Brain and Behaviour Institute, Department of Psychiatry and Neuropsychology, Universiteit Maastricht, The Netherlands

Address correspondence to: Dr. A. Honig, Brain and Behaviour Institute, Maastricht University, Department of Psychiatry, Academic Hospital Maastricht (AZM), P.O. Box 5800, 6202 AZ Maastricht, The Netherlands. Tel.: ${ }^{*} 3143$ 3877537; Fax: *31 43 3875444; E-mail: adriaan.honig@spsy.azm.nl

Received June 21, 2001; revised April 10, 2002; accepted April 12, 2002.

Online publication: 4/12/02 at www.acnp.org/citations/ Npp041202283. ing dysfunction of the serotonergic system. Increased platelet serotonin (5-hydroxytryptamine or 5-HT), a lower maximal velocity (Vmax) of 5-HT platelet uptake and decreased central serotonergic neurotransmitter activity, indicated by decreased 5HIAA/5-HT ratios, have been reported in untreated bipolar depressed patients (Wirz Justice and Puhringer 1978; Marazziti et al.1991; Leake et al. 1991; Young et al. 1994). Polymorphism in the 5-HT-transporter, 5-HT receptors and the tryptophan hydroxylase gene have been associated with the pathophysiology of BD (Kunugi et al. 1997; Oruc et al. 1997; Bellivier et al. 1998).

Acute tryptophan depletion (ATD) is a direct method to investigate central serotonergic vulnerability (Delgado et al. 1994). In this procedure, a lowering of central 
5-HT synthesis is accomplished by giving subjects a 50$100 \mathrm{~g}$ balanced amino acid-drink (AA-drink), composed of amino acids, including large neutral amino acids (LNAAs: tyrosine, valine, leucine, isoleucine and phenylalanine), and devoid of tryptophan (Trp) (Young 1991). In remitted depressed patients, ATD induced depressive symptoms (Smith et al. 1997; Aberg-Wistedt et al. 1998; Moreno et al. 2000). In healthy first-degree relatives of depressed patients, ATD induced a modest lowering of mood, compared with healthy control subjects (Benkelfat et al. 1994; Klaassen et al. 1999). It thus appears that individuals without prior depressive episodes, but at a genetic risk for depression, may be biologically predisposed to mood-lowering effects of ATD.

Until now, little attention has been paid to the effects of ATD in BD, and results are inconsistent (Sobczak et al. 2000). Cappiello et al. (1997) reported a significant increase in manic symptoms in recently remitted (one month) lithium-treated manic patients. In BD patients who were stable for a longer period (1-15 years), ATD did not induce significant mood changes (Benkelfat et al. 1995; Cassidy et al. 1998; Hughes et al. 2000).

In BD patients abnormalities in cortisol homeostasis has been described. Cortisol may therefore be used as a biological marker of BD. Serotonin increases cortisol release by stimulating $5-\mathrm{HT}_{1 \mathrm{~A}}$ and $5-\mathrm{HT}_{2 \mathrm{~A}}$ receptors in hippocampal areas (Nurnberger et al. 1990; Swann et al. 1992; Vieta et al. 1999). Changes in cortisol following challenge with selective 5-HT stimulating agents are possible biological markers to assess brain 5-HT function (Abel and Cleare 1999; Cleare et al. 1998). A blunted cortisol response following an intravenous Trp challenge in BD patients, as compared with controls, provides evidence for brain 5-HT dysfunction (Nurnberger et al. 1990). To our knowledge, the effects of ATD on stress-induced cortisol release have never been described, but might provide an important indicator of central 5-HT vulnerability. Symptoms (according to DSM IV) of BD psychopathology might contribute to effects of ATD. Therefore we differentiated between relatives of BD type I and BD type II patients. This study is the first family history $(\mathrm{FH})$ study of 5-HT vulnerability in which such a distinction was made between first-degree relatives of type I (FH I) and type II BD (FH II) patients.

To gain additional insight into the nature of this biological vulnerability, the current study investigated serotonergic vulnerability, as reflected in mood and cortisol responses to ATD in healthy first-degree relatives of BD patients (FH). ATD effects in FH subjects were compared with those in healthy matched controls. We hypothesized central serotonergic vulnerability in FH subjects to be reflected by: (1) an elevation in mood, as has been reported in BD patients; (2) more pronounced blunting of stressinduced cortisol release following ATD compared with controls; and (3) mood and cortisol effects of ATD were hypothesized to be different in FH I and FH II subjects.

\section{METHODS}

\section{Subjects}

Subjects were first-degree relatives of BD patients and healthy matched controls (see Table 1). Family members were recruited through BD patients in treatment at the Department of Psychiatry, University Hospital Maastricht, by the consumer organization for manicdepressive patients and their families, and by advertisements in local newspapers. Healthy control subjects were also recruited by a newspaper advertisement.

Of the 47 subjects who enrolled in the study, 2 subjects in the $\mathrm{FH}$ group were excluded during the experiment because of intolerance of the drink.

The included subjects were $30 \mathrm{FH}(8$ men and 22 women) and 15 controls (4 men, 11 women), aged 19-64 years. Table 1 shows demographic characteristics of all subjects who completed the experiment. Relatives were daughters $(n=11)$, sons $(n=4)$, siblings $(n=4)$, mothers $(n=8)$ and fathers $(n=3)$. Nineteen subjects had a first-degree relative with a BD type I diagnosis, and eleven subjects were relatives of BD type II patients. Control subjects were successfully matched to $\mathrm{FH}$ subjects with respect to age, body mass index (BMI) and intelligence quotient (IQ). There were no differences between FH subjects and controls with respect to number of premenopausal versus postmenopausal women or to use of oral anticonceptives or other medication. Overall, 22 female subjects were premenopausal and 11 were postmenopausal. Seven women used oral anticonceptives. Seven subjects were taking medication with no interference on ATD or cortisol.

Table 1. Demographic characteristics, bipolar disorder family loading $\left(1^{\text {st }}, 2^{\text {nd }}\right.$ and $3^{\text {rd }}$ degree $)$, SCL-90, Young Mania Rating Scale (YMRS), Hamilton Depression Rating Scale (HDRS), total scores and General Behavior Inventory (GBI) scores of the subjects; mean $( \pm \mathrm{SE})$

\begin{tabular}{lcc}
\hline & FH & Controls \\
\hline Women & $\mathrm{n}=22$ & $\mathrm{n}=11$ \\
Men & $\mathrm{n}=8$ & $\mathrm{n}=4$ \\
Rel. of Type I & $\mathrm{n}=19$ & \\
Rel. of Type II & $\mathrm{n}=11$ & \\
Family members: & & \\
Bipolar disorder & 1.3 & 0.0 \\
Age* & $41.4 \pm 2.6$ & $40.3 \pm 4.0$ \\
IQ* & $117.2 \pm 2.0$ & $117.3 \pm 4.1$ \\
BMI* & $24.7 \pm 0.6$ & $24.3 \pm 0.9$ \\
SCL-90* & $103.5 \pm 2.4$ & $100.3 \pm 2.7$ \\
$\quad$ depression* & $18.6 \pm 0.6$ & $17.1 \pm 0.3$ \\
YMRS* & $1.2 \pm 0.4$ & $0.9 \pm 0.4$ \\
HDRS* & $1.4 \pm 0.3$ & $1.2 \pm 0.4$ \\
GBI & & \\
$\quad$ depression* & $55.7 \pm 1.7$ & $53.6 \pm 2.7$ \\
mania/hypomania* & $23.9 \pm 0.7$ & $24.6 \pm 1.8$ \\
biphasic* & $8.3 \pm 0.4$ & $8.3 \pm 0.7$ \\
\hline *mean \pm SE & &
\end{tabular}




\section{Design}

The study used a placebo-controlled, double blind, crossover design. The within subjects-factor, treatment condition, consisted of 2 levels: placebo and ATD. The order of treatment was balanced over two test days, spaced one to two weeks apart. The between-subjects factor $\mathrm{FH}$ differentiated subjects with $(\mathrm{FH})$ or without (controls) at least one first-degree relative with BD. A further distinction was made between having a relative with a type I or type II BD (FH I vs. FH II).

To eliminate possible bias due to premenstrual symptoms, all premenopausal women were tested in the follicular phase of the menstrual cycle (Menkes et al. 1994; Rasgon et al. 2000).

\section{Amino Acid Mixtures}

The Trp-deficient AA-drink contained a total of $75 \mathrm{~g}$ of different amino acids with the amounts of each specific amino acid according to the proportions described by Young et al. (1985): $4.1 \mathrm{~g}$ L-alanine, $2.4 \mathrm{~g}$ glycine, $2.4 \mathrm{~g}$ L-histidine, $6.0 \mathrm{~g}$ L-isoleucine, $10.1 \mathrm{~g}$ L-leucine, $6.7 \mathrm{~g}$ L-lysine, $4.3 \mathrm{~g}$ L-phenylalanine, $9.2 \mathrm{~g}$ L-proline, $5.2 \mathrm{~L}$-serine, $4.3 \mathrm{~g}$ L-threonine, $5.2 \mathrm{~g}$ L-tyrosine, $6.7 \mathrm{~g}$ L-valine, $3.7 \mathrm{~g}$ L-arginine, $2.0 \mathrm{~g}$ L-cysteine, $3.0 \mathrm{~g}$ L-methionine. The placebo mixture contained the same amino acids, plus $3.0 \mathrm{~g}$ tryptophan. To provide caloric energy, $20 \mathrm{~g}$ of a maltodextrin (MD/ fat mix) (33\% sunflower and 67\% maltodextrin) was added. Both drinks were prepared by adding $300 \mathrm{ml}$ tap water with the addition of strawberry or banana flavoring to compensate for the unpleasant taste (see also Schmitt et al. 2000).

\section{Procedure}

Subjects. In the FH group, the main inclusion criterion was having at least one first-degree relative with BD. Control subjects were free of any psychopathologic family loading. To assess FH, all subjects were interviewed with an abbreviated version of the Family History Research Diagnostic Criteria (FHRDC) (Endicott et al. 1975). Individual diagnoses (type I or type II BD, according to DSM IV) of the patients were verified via each patient's own psychiatrist.

All participants were given a standardized psychiatric examination (Mini International Neuropsychiatric Interview; MINI) (Sheehan et al. 1994) to determine the present psychiatric state, according to DSM IV criteria. The 17-item Hamilton Depression Rating Scale (HDRS) (Hamilton 1967), the Young Mania Rating Scale (YMRS) (Young et al. 1978) and the SCL-90 (Arrindell and Ettema 1986) were used to verify the absence of depressive, manic and general psychiatric symptomatology. As an extra check on psychopathology, all subjects filled out the General Behavior Inventory (GBI), which identifies lifetime sub-clinical affective symp- toms (Depue et al. 1981, 1985, 1989; Klein et al.1986). Included control and FH subjects did not differ on GBI scores, which meant that they were successfully matched (see Table 1).

Exclusion criteria were current or past use of psychopharmacological medication, lifetime psychiatric disorder including alcohol or drug abuse, current active physical illness, lactation and pregnancy. Physical health was assessed by means of a health questionnaire, a standard physical examination by a physician and a urine screening. The urine test (Combur $\left.{ }^{\circledR}\right)$ included assessment of leukocytes, nitrite, $\mathrm{pH}$, protein, glucose, ketones, urobilinogen, bilirubin and erythrocytes. A Quick View one-step pregnancy test (Quidel ${ }^{\circledR}$ ) was carried out in female subjects to check for unsuspected pregnancy.

One control subject was matched with two FH subjects with respect to sex, age, BMI and IQ. Intelligence (IQ) was estimated using Groninger Intelligence Test (GIT) subtasks (Vocabulary, Mental Rotation, Mental Arithmetic and Word Analogies) (Luteijn 1966).

The Medical Ethics Committee of the Academic Hospital of Maastricht approved the study. All participants gave written informed consent.

The Test Days. On each test day, the subjects arrived at 8:30 A.M. after an overnight fast. At 10:00 A.M. $\left(\mathrm{t}_{0}\right)$ (all timepoints $t_{(-) x}$ refer to a time $x$ hours (before) after $t_{0}$ ) the subjects were administered the AA-drink, which had to be consumed within two hours. At $t_{2}$, all subjects ate a protein-poor lunch which consisted of protein-free bread, tomatoes, marmalade, apples, oranges and herbal tea or decaffeinated coffee.

Mood assessment was completed at baseline at 8:45 A.M. $\left(t_{-1.25} Q 5\right)$, and at $t_{5}$ and $t_{7}$. The stress-inducing speech task (SIST) started at $t_{6.75}$, when the effects of ATD were expected to be present. Three baseline cortisol measurements were collected before the SIST, at $t_{5}, t_{6.5}$ and $t_{6.75}$. After the SIST, saliva cortisol samples were taken every 15 minutes; at $t_{7}, t_{7.25}, t_{7.5}$ and finally at $t_{7.75}$. Previous studies (van Eck et al. 1996) showed cortisol response to the SIST to be maximal during this time interval.

Blood samples were taken twice, at $t_{0}$ and at $t_{6.5}$. Blood pressure and pulse rate were assessed before mood rating at $t_{0}$, and at $t_{5}$.

\section{Mood Assessments}

Mood was assessed with the abbreviated bimodal Profile of Mood States (POMS) (McNair et al. 1971) and the Bond and Lader (B\&L) (Bond and Lader 1974) visual analog scales.

The POMS consists of 32 bipolar sets of adjectives, which measure five mood dimensions: anger, depression, fatigue, tension and vigor.

The B\&L is composed of 16 mood items, which measure alertness, contentment, and calmness. 


\section{Stress-inducing Speech Task}

The SIST consisted of a 5-min oral presentation, in front of a video-camera, preceded by $10 \mathrm{~min}$ of preparation. In a slightly modified version of the task used by van Eck et al. (1996), subjects were first given a list of four mood terms. Three parallel versions of the list were available. Subjects were instructed to elaborate on personal experiences evoked by these mood terms and were told that the speech would be video-recorded for later evaluation by a panel of psychiatrists and psychologists (van Eck et al. 1996; Nicolson et al. 1997). After the screening a SIST practice session, in which an identical version of the mood term list was used. At the end of the second test day subjects were debriefed.

\section{Salivary Cortisol Measurements}

Saliva was collected with a cotton roll (Salivette $₫$, Sarstedt). Uncentrifuged samples were stored at $-20^{\circ} \mathrm{C}$ until analysis. Free cortisol levels were determined in duplicate by direct radioimmunoassay, using a highperformance liquid chromatography high performance liquid chromatography (HPLC)-purified preparation of cortisol-3-CMO-histamine ${ }^{125}$ I (Ansseau et al. 1984; Sulon, personal communication).

\section{Somatic Side Effects}

Severity of side effects was determined by a questionnaire with 17 items rated on 4-point scales. The total sum of reported complaints represents the overall severity of side effects.

\section{Serum Amino Acids}

Serum was taken by venipuncture in sodium heparin tubes. Blood samples were immediately set on ice and centrifuged (3000 rpm, $10 \mathrm{~min}$ ) within one hour. Plasma samples were mixed with sulfasalicyl acid and frozen at $-80^{\circ} \mathrm{C}$ until analysis. Total concentrations of plasma Trp and ratio of Trp:LNAAs were determined by HPLC (van Eijk et al. 1993).

\section{Statistical Analysis}

Outcome variables were analyzed using General Linear Model (GLM) for repeated measures. Within-subjects factor was treatment (two levels: ATD or placebo); the between-subjects factor was family history (three levels: controls, FH I, or FH II). Univariate contrasts were used to test the primary hypothesis of difference between controls and FH subjects (controls vs. FH I + II) as well as the hypotheses of differences between controls and FH I and FH II relatives separately (controls vs. FH I and controls vs. FH II). Differences in baseline values between test sessions were assessed using GLM. When no baseline differences were found, baseline values were left out of analyses.

Cortisol values were ${ }^{10} \log$-transformed prior to statistical testing, since cortisol distributions were skewed. Missing values were corrected by using mean of previous and next cortisol values. Wilcoxon Matched-Pairs Signed-Ranks Test was used to test differences in physical complaints. Statistical analyses were performed with SPSS 9.0 for Windows.

\section{RESULTS}

\section{Plasma Trp Levels}

Due to procedural difficulties $1.4 \%$ of serum samples were missing.

Plasma Trp concentrations and ratio Trp:LNAAs did not differ at baseline between groups or treatment conditions, but decreased significantly $\left[\mathrm{F}_{1,28}=151.11\right.$, $p<.001]$ over time in the ATD condition. Relative to baseline, ATD resulted in a 57\% decrease in plasma Trp and a 70\% decrease in ratio Trp:LNAAs. After receiving placebo, there was a $36 \%$ increase in plasma Trp and 1.0\% increase in the ratio Trp:LNAAs. Results are summarized in Figure 1.

\section{Subjective Mood Ratings}

One subject was excluded from the analyses due to 2 missing POMS scores.

At baseline, POMS scores did not differ significantly between $\mathrm{FH}$ and controls or experimental conditions. Figure 2 shows the mood response after ATD compared with placebo. Controls and FH I did not differ in ATD induced mood response, but compared with these groups, FH II subjects reported an overall improvement in mood, indicated by the POMS total score $\left[\mathrm{F}_{2,40}=3.35\right.$, $p<.05]$, a decrease in fatigue $\left[\mathrm{F}_{2,40}=3.65, p<.05\right]$ and a trend toward lower anger $\left[\mathrm{F}_{2,40}=3.13, p<.1\right]$. This is an overall effect; within each FH group mood changes following ATD were not significant. There was no main effect of ATD, overall interaction effect of FH with ATD, or effect of treatment order.

Scores on B\&L subscales did not differ at baseline and after ATD between experimental conditions or FH groups.

\section{Cortisol Measurements}

Cortisol Response to the SIST. In both ATD and placebo conditions, cortisol levels increased over time in response to the SIST $\left[\mathrm{F}_{6,36}=3.60, p<.05\right]$. A cortisol peak occurred immediately after the speech $\left(\mathrm{t}_{7}\right)$. Compared with prespeech levels $\left(t_{5}\right)$, cortisol was increased by a mean of $21 \%$. The three groups did not differ in pre-speech cortisol levels or in the magnitude of the SIST-induced cortisol response. 
Ratio L-Trp: LNAA's

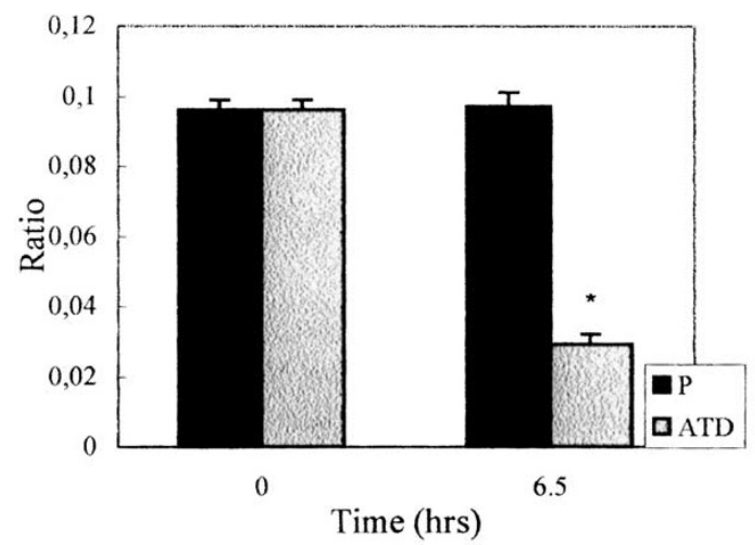

Plasma Trp

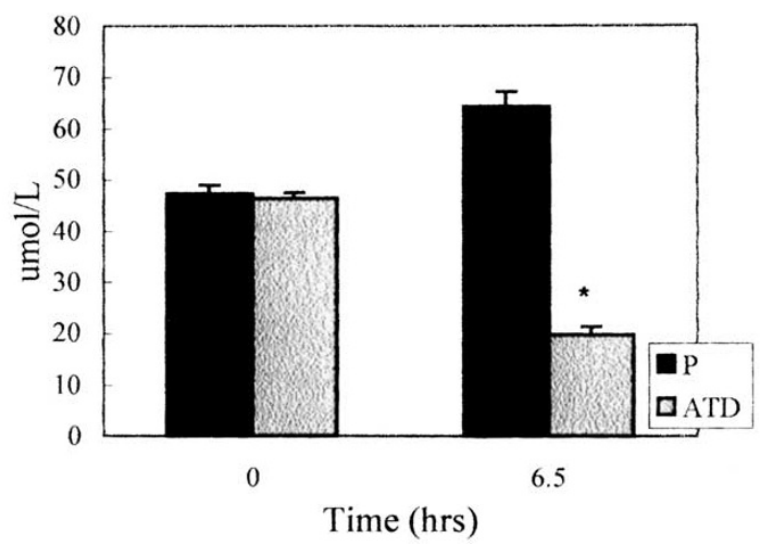

Figure 1. Mean ( \pm SE) serum ratio Trp: LNAAs (left) and Trp concentrations (right), at $\mathrm{t}_{0}$ and $\mathrm{t}_{6.5} \cdot{ }^{*} p=.05$.

Effects of ATD. Figure 3 shows the effect of ATD on cortisol release compared with placebo (the cortisol values in the placebo condition were subtracted). In FH subjects (both FH I and FH II), ATD resulted in a significant decrease in cortisol $\left[\mathrm{F}_{1,28}=5.26, p<.05\right]$ compared with placebo. In controls, cortisol was higher after ATD compared with placebo. There were no effects of treatment order.

Of the 630 cortisol samples, $0.4 \%$ were missing; two subjects (one $\mathrm{FH}$ and one control) were not included in cortisol data analyses, because of extremely high cortisol levels (above $44 \mathrm{nmol} / \mathrm{l}$ ) probably in response to difficulties in taking blood.
Somatic Side Effects. Sum of reported side effects did not differ at baseline or between the two experimental conditions. Correlation analysis of B\&L and POMS mood ratings with side effects revealed no significant correlations of sum complaints with mood changes following ATD.

\section{Intercorrelations}

Pearson's correlation analyses showed no significant associations between ATD-induced cortisol response and changes in mood ratings.

\section{Difference POMS Total score (P minus ATD)}

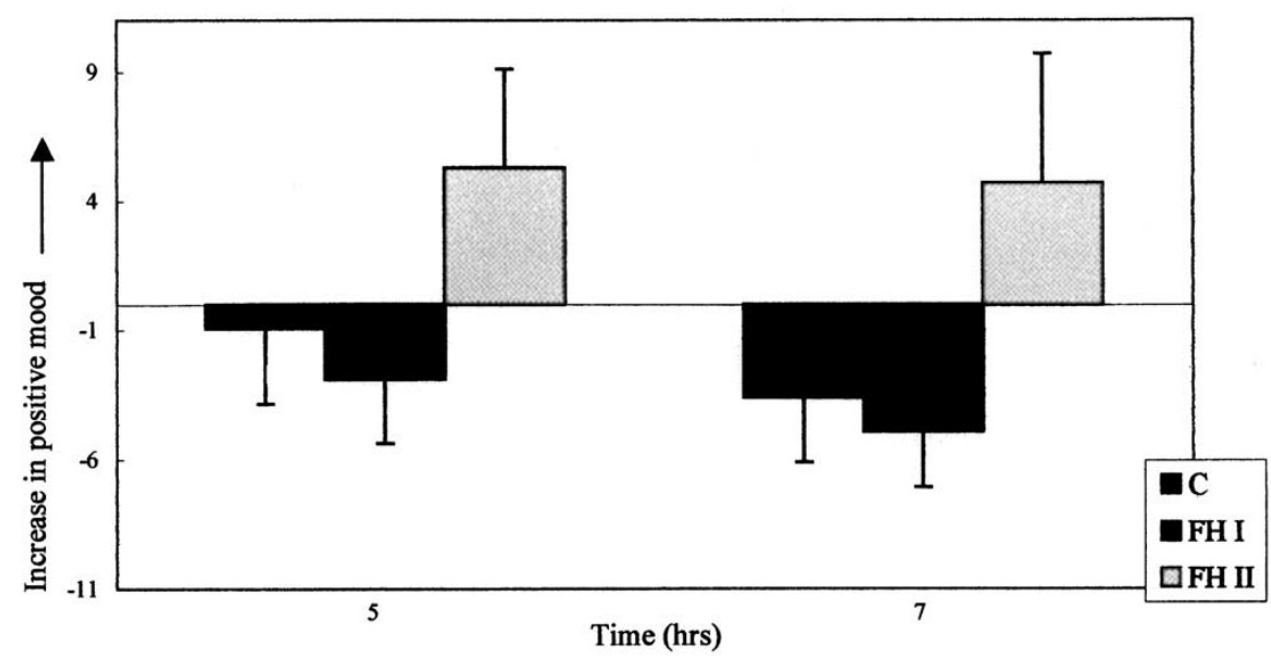

Figure 2. Effect (mean $\pm \mathrm{SE}$ ) of type BD (C, control subjects; first-degree relatives; FH I and FH II subjects) and ATD on POMS total score at $t_{5}$ and $t_{7}$. Values are corrected for placebo $(\mathrm{P})$. 


\section{Effects of ATD on cortisol (ATD minus P)}

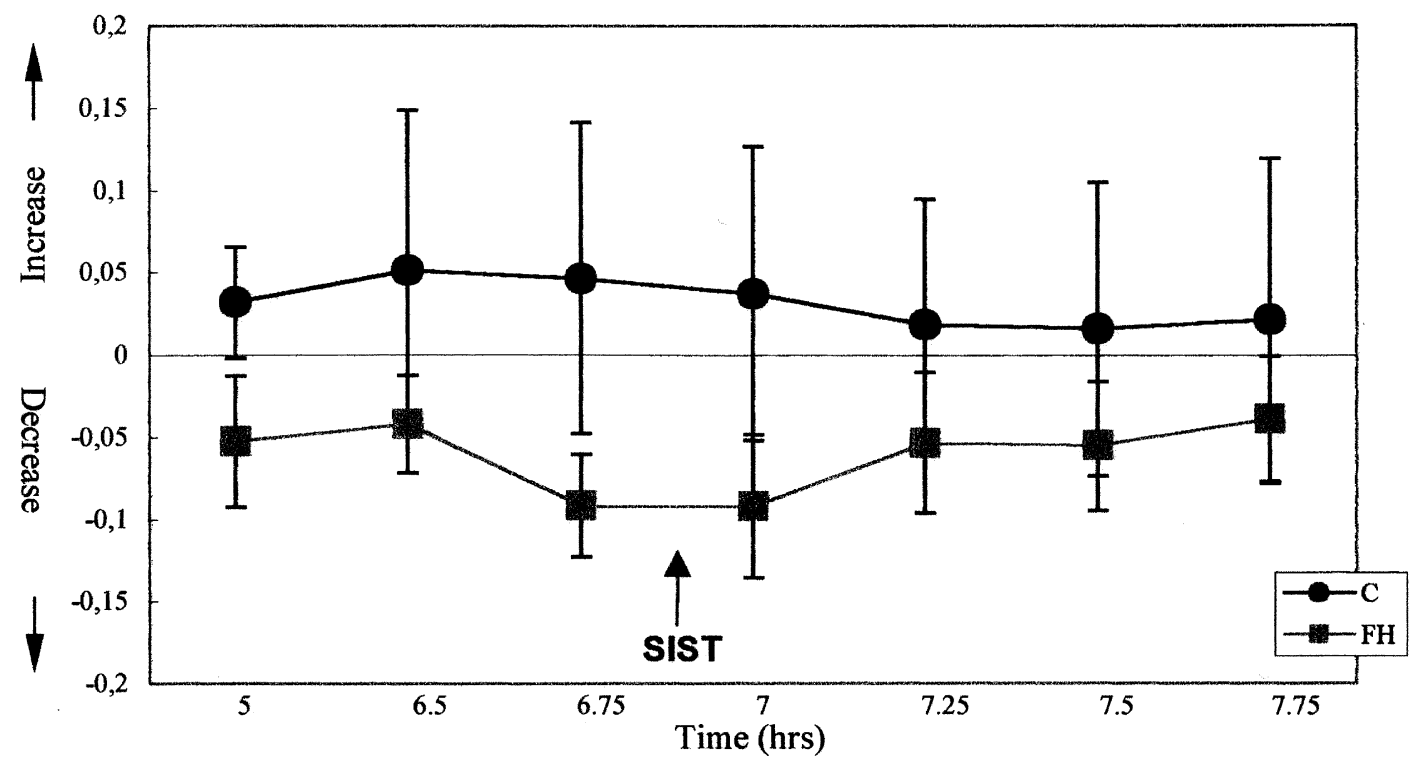

Figure 3. SIST-induced cortisol response after ATD (mean $\pm \mathrm{SE}$ ), expressed as difference from the placebo (P) condition. Effect of family history (FH) (C, control subjects) on salivary cortisol $\left({ }^{10} \log\right.$ concentration: $\left.\mu \mathrm{g} / \mathrm{dl}\right)$.

\section{DISCUSSION}

The aim of the study was to investigate central 5-HT vulnerability in first-degree relatives of BD patients following a double-blind placebo-controlled ATD paradigm. Plasma ratio Trp:LNAAs and Trp decreased significantly, which indicates an adequate ATD. Tyrosine availability did not appear to have interfered with the effects of ATD, as levels did not differ between experimental conditions.

We found no overall differences between controls and FH subjects in ATD-induced mood response. However, FH II subjects reported a tendency to mood elevation, whereas FH I subjects and controls experienced a slight mood lowering following ATD. Side effects were unlikely to have interfered with mood changes after ATD, as the sum of reported side effects did not differ between ATD and placebo.

There are no studies available that describe effects of ATD on different types of BD. Our results are in line with a previous report of elevated mood following ATD in recently remitted BD patients, who were not further differentiated as type I or type II (Cappiello et al. 1997).

Previous studies of ATD in BD patients suggest that $\mathrm{BD}$ patients who were recently in remission were more vulnerable to the effects of ATD compared with BD patients who were in remission for a longer period (Benkelfat et al. 1995; Cappiello et al. 1997). It was suggested that successful short-term lithium treatment was more dependent on 5-HT availability than successful longterm prophylaxis with lithium. This implies a strong in- fluence of 'state' variables on vulnerability to ATD in BD patients. However previous studies on ATD in BD patients did not include healthy subjects as a control group and drawing conclusions about 'trait' influence on mood changes following ATD is therefore hampered.

ATD-induced mood lowering in depressed patients and their first-degree relatives suggest central serotonergic vulnerability (Klaassen et al. 1999; Delgado et al. 1991). We suggest that mood changes after ATD in FH II subjects might be explained by the same vulnerability. The discrepancy that FH II of BD patients report an increase in mood, whereas relatives of unipolar patients report a decrease in mood, may possibly be due to vulnerability to mania in FH II subjects. Both mania and depression have been associated with hyposerotonergic activity (Goodwin and Ghaemi 1990; Price et al. 1990; Young et al. 1994).

Suicide has also been associated with low central 5-HT (Pfeffer et al. 1998; Asberg 1997). Meltzer et al. (1984) described an increased serotonergic vulnerability in depressed patients with a history of suicidal activity. Higher rates of suicide has been described in BD type II compared with BD type I patients (Rihmer and Pestality 1999). It is speculated that suicide is another independent factor which may contribute to serotonergic vulnerability in BD type II psychophysiology.

Compared with controls, FH I subjects did not show mood changes after ATD, which may suggest a biological distinction between BD type I and type II. FH I subjects are characterized by cognitive deficits (Sobczak et al. 
2002). Cognitive dysfunctions in BD patients show a pattern similar to schizophrenia (Krabbendam et al. 2000). Cognitive deficits have been described in FH I and not in FH II subjects (Sobczak et al. 2002). It was suggested that BD type I subjects share more similarities with a primary psychotic spectrum whereas BD type II is characterized by primary affective symptoms. This hypothesis appears to be consistent with the absence of mood changes observed in schizophrenic patients after ATD (Sharma et al. 1997). Inconsistent findings of previous studies on ATD in BD may possibly be due to a failure to take differences in BD type I and BD type II into account.

The significant decrease in cortisol release in FH subjects following ATD suggests a 5-HT vulnerability in FH subjects affecting the HPA-axis. Decrease in cortisol response is consistent with previous described changes in 5-HT responsivity in BD (Vieta et al. 1999). A blunted cortisol response has been described in $\mathrm{BD}$ compared with controls following intravenous Trp challenge (Nurnberger et al. 1990).

ATD-induced blunted cortisol response might have been attenuated due to the weak stress-inducing effect of the SIST procedure. The cortisol peak after the SIST $(21 \%)$ was modest compared with the previously reported ( \pm ) $90 \%$ increase in saliva cortisol concentrations (van Eck et al. 1996) possibly due to procedural differences in our experiment. First, we used a modified and perhaps less stressful version of the SIST; in the study by van Eck et al. (1996), subjects were unaware that they would be asked to deliver a speech. Second, our subjects underwent the SIST 3 times: once as a training procedure, once after ATD, and once after placebo.

The ATD-induced mood changes are not likely to be attributable to changes in cortisol release. First, correlation analyses revealed no significant association. Second, the reported mood changes were specific for FH II subjects, whereas the cortisol response did not differ between FH I or FH II subjects. Third, mood ratings showed no differences between assessments immediately before and after the SIST.

In conclusion, this study provides evidence for 5-HT vulnerability affecting the HPA-axis and mood in $\mathrm{FH}$ subjects. The 5-HT vulnerability affecting mood was present only in FH II subjects and not in FH I subjects. This is consistent with a primarily psychotic psychopathology in BD type I and a primarily affective psychopathology in BD type II patients.

These findings should be replicated in a larger research population with BD type I and type II patients as well as their relatives.

\section{ACKNOWLEDGMENTS}

This study was made possible by a grant from the Theodore and Vada Stanley Foundation.

\section{REFERENCES}

Abel KM, Cleare AJ (1999): Peripheral hormonal responses to D-fenfluramine as a probe of central serotonergic function in humans. Psychopharmacol 142:68-72

Aberg-Wistedt A, Hasselmark L, Stain-Malmgren R, Aperia B, Kjellman BF, Mathe AA (1998): Serotonergic vulnerability in affective disorder: a study of the tryptophan depletion test and relationships between peripheral and central serotonin indexes in citalopram-responders. Acta Psychiatr Scand 97:374-380

Ansseau M, Sulon J, Doumont A, Cerfontaine JL, Legros JJ, Sodoyez JC, Demey-Ponsart E (1984): Use of saliva cortisol in the dexamethasone suppression test. Psychiatry Res 13:203-211

Arrindell WA, Ettema JHM (1986): SCL-90. Een multidimensionele psychopathologie indicator [SCL-90. A multidimensional indicator of psychopathology]. Swets \& Zeitlinger, Lisse, The Netherlands

Asberg M (1997): Neurotransmitters and suicidal behavior. The evidence from cerebrospinal fluid studies. Ann N Y Acad Sci 836:158-181

Bellivier F, Leboyer M, Courtet P, Buresi C, Beaufils B, Samolyk D, Allilaire J, Feingold J, Mallet J, Malafosse A (1998): Association between the tryptophan hydroxylase gene and manic-depressive illness. Arch Gen Psychiatry 55:33-37

Benkelfat C, Ellenbogen MA Dean P, Palmour RM, Young SN (1994): Mood-lowering effect of tryptophan depletion. Enhanced susceptibility in young men at genetic risk for major affective disorders. Arch Gen Psychiatry 51:687-697

Benkelfat C, Seletti B, Palmour RM, Hillel J, Ellenbogen M, Young SN (1995): Tryptophan depletion in stable lithium-treated patients with bipolar disorder in remission [letter; comment]. Arch Gen Psychiatry 52:154-156

Bond A, Lader M (1974): The use of analogue scales in rating subjective feelings. Br J Med Psych 80:1-46

Cappiello A, Sernyak MJ, Malison RT, McDougle CJ, Heninger GR, Price LH (1997): Effects of acute tryptophan depletion in lithium-remitted manic patients: a pilot study. Biol Psychiatry 42:1076-1078

Cassidy F, Murry E, Carroll BJ (1998):Tryptophan depletion in recently manic patients treated with lithium. Biol Psychiatry 43:230-232

Cleare AJ, Murray RM, Sherwood RA, O'Keane V (1998): Abnormal 5-HT1D receptor function in major depression: a neuropharmacological challenge study using sumatriptan. Psychol Med 28:295-300

Delgado PL, Price LH, Miller HL, Salomon RM, Aghajanian GK, Heninger GR, Charney DS (1994): Serotonin and the neurobiology of depression. Effects of tryptophan depletion in drug-free depressed patients. Arch Gen Psychiatry 51:865-874

Delgado PL, Price LH, Miller HL, Salomon RM, Licinio J, Krystal JH, Heninger GR, Charney DS (1991): Rapid serotonin depletion as a provocative challenge test for patients with major depression: relevance to antidepressant action and the neurobiology of depression. Psychopharmacol Bull 27:321-330 
Depue RA, Slater J, Wolfstetter-Kausch H, Klein D, Goplerud E, Farr D (1981): A behavioral paradigm for identifying persons at risk for bipolar depressive disorder: A conceptual framework and five validation studies [Monograph]. J Abnorm Psychol 90:381-437

Depue RA, Kleiman RM, Davis P, Hutchinson M, Krauss SP (1985): The behavioral high-risk paradigm and bipolar affective disorder, VIII: Serum cortisol in nonpatient cyclothemic subjects selected by the general behavior inventory. Am J Psychiatry 142:175-181

Depue RA, Krauss S, Spoont MR, Arbisi P (1989): General behavior inventory identification of unipolar and bipolar affective conditions in a nonclinical university population. J Abnorm Psychol 98:117-126

Endicott J, Andreasen NC, Spitzer RL (1975): Family History -Research Diagnostic Criteria. New York, Biometrics Research, New York State Psychiatric Institute

Goodwin F, Ghaemi SN (1998): Understanding manicdepressive illness. Arch Gen Psychiatry 55:23-25

Hamilton M (1967): Development of a rating scale for primary depressive illness. Br J Soc Clin Psychol 6:278-296

Hughes JH, Dunne F, Young AH (2000): Effects of acute tryptophan depletion on mood and suicidal ideation in bipolar patients symptomatically stable on lithium. Br J Psychiatry 177:447-451

Klaassen T, Riedel WJ, van Someren A, Deutz NEP, Honig A, van Praag HM (1999): Mood effects of 24-hour tryptophan depletion in healthy first degree relatives of patients with affective disorders. Biol Psychiatry 46:489-497

Klein D, Depue RA, Slater J (1986): Inventory identification of cyclothymia: IX. Validation in offspring of bipolar I patients. Arch Gen Psychiatry 43:441-445

Krabbendam L, Honig A, Wiersma J, Vuurman EFPM, Hofman PAM, Derix MMA, Nolen WA, Jolles J (2000): Cognitive dysfunctions and white matter lesions in patients with bipolar disorder in remission. Acta Psychiatr Scand 101:274-280

Kunugi H, Hattori M, Kato T, Tatsumi M, Sakai T, Sasaki T, Hirose T, Nanko S (1997): Serotonin transporter gene polymorphisms: ethnic difference and possible association with bipolar affective disorder. Mol Psychiatry 2:457-462

Leake A, Fairbairn AF, McKeith IG, Ferrier IN (1991): Studies on the serotonin uptake binding site in major depressive disorder and control post-mortem brain: Neurochemical and clinical correlates. Psychiatry Res 39:155-165

Luteijn F (1966): Een nieuwe verkorte versie van de Groningen Intelligentie Test [A new abbreviated Groninger Intelligence Test]. Ned Tijdschr Psychol 21:675-682

Marazziti D, Lenzi A, Cassano GB (1991): Serotoninergic dysfunction in bipolar disorder. Pharmacopsychiatry 24:164-167

McNair DM, Lorr M, Droppleman LF (1971): Manual for the profile of mood states. San Diego, CA, Educational and Industrial Testing Services.

Meltzer HY, Perline R, Tricou BJ, Lowy M, Robertson A (1984): Effect of 5-hydroxytryptophan on serum cortisol levels in major affective disorders. II. Relation to sui- cide, psychosis, and depressive symptoms. Arch Gen Psychiatry 41:379-387

Menkes DB, Coates DC, Fawcett JP (1994): Acute tryptophan depletion aggravates premenstrual syndrome. J Affect Disord 32:37-44

Moreno FA, Heniger GR, McGahuey CA, Delgado PL (2000): Tryptophan depletion and risk of depression relapse: a prospective study of tryptophan depletion as a potential predictor of depressive episodes. Biol Psychiatry 48:327-329

Nicolson N, Storms C, Ponds R, Sulon J (1997): Salivary cortisol levels and stress reactivity in human aging. J Geront: Med Sci 52A:M68-M75

Nordstrom P, Samuelsson M, Asberg M, Traskman-Bendz L, Asberg-Wistedt A, Nordin C, Bertilsson L (1994): CSF 5-HIAA predicts suicide risk after attempted suicide. Suicide Life Threat Behav 24:1-9

Nurnberger JI Jr, Berrettini W, Simmons Alling S, Lawrence D, Brittain H (1990): Blunted ACTH and cortisol response to afternoon tryptophan infusion in euthymic bipolar patients. Psychiatry Res 31:57-67

Oruc L, Verheyen GR, Furac I, Jakovljevic M, Ivezic S, Raeymaekers P, Van Broeckhoven C (1997): Association analysis of the 5-HT2C receptor and 5-HT transporter genes in bipolar disorder. Am J Med Genet 74:504-506

Pfeffer CR, McBride PA, Anderson GM, Kakuma T, Fensterheim L, Khait V (1998): Peripheral serotonin measures in prepubertal psychiatric inpatients and normal children: associations with suicidal behavior and its risk factors. Biol Psychiatry 44:568-577

Price LH, Charney DS, Delgado PL, Heniger GR (1990): Lithium and serotonin function:implications for the serotonin hypothesis of depression. Psychopharmacol 100:3-12

Rasgon N, McGuire M, Tanavoli S, Fairbanks L, Rapkin A (2000): Neuroendocrine response to an intravenous L-tryptophan challenge in women with premenstrual syndrome. Fertil Steril 73:144-149

Rihmer Z, Pestality P (1999): Bipolar II disorder and suicidal behavior. Psychiatr Clin North Am 22:667-673

Schmitt JAJ, Jorissen BL, Sobczak S, Van Boxtel MPJ, Hogervorst E, Deutz NEP, Riedel WJ (2000): Tryptophan depletion impairs memory consolidation, but improves focused attention in healthy young volunteers. J Psychopharmacol 14:21-29

Sharma RP, Shapiro LE, Kamath SK, Soll EA, Watanabe MD, Davis JM (1997): Acute dietary tryptophan depletion: effects on schizophrenic positive and negative symptoms. Neuropsychobiology 35:5-10

Sheehan D, Lecrubier Y, Janavs J, Knapp E, Weiller E (1994): MINI international Neuropsychiatric Interview. Tampa, FL, University of South Florida

Smith KA, Fairburn CG, Cowen PJ (1997): Relapse of depression after rapid depletion of tryptophan. Lancet 349:915-919

Sobczak S, Honig A, Riedel WJ (2000): Acute tryptophan depletion in bipolar disorders; literature review and directives for further research. Acta Neuropsychiatrica 12:69-72

Sobczak S, Riedel WJ, Booij L aan het Rot M, Deutz NEP Honig A (2002): Cognition following acute tryptophan 
depletion: differences between first-degree relatives of bipolar disorder patients and matched healthy control volunteers. Psychol Med 32:503-515

Swann AC, Stokes PE, Casper R, Secunda SK, Bowden CL, Berman N, Katz MM, Robins E (1992): Hypothalamicpituitary-adrenocortical function in mixed and pure mania. Acta Psychiatr Scand 85:270-274

van Eck MM, Nicolson NA, Berkhof H, Sulon J (1996): Individual differences in cortisol responses to a laboratory speech task and their relationship to responses to stressful daily events. Biol Psychol 43:69-84

van Eijk HM, Rooyakkers DR, Deutz NE (1993): Rapid routine determination of amino acids in plasma by high-performance liquid chromatography with a 2-3 microns Spherisorb ODS II column. J Chromatogr 620:143-148

Vieta E, Martinez-De-Osaba MJ, Colom F, Martinez-Aran A, Benabarre A, Gasto C (1999): Enhanced corticotropin response to corticotropin-releasing hormone as a pre- dictor of mania in euthymic bipolar patients. Psychol Med 29:971-978

Wirz Justice A, Puhringer W (1978): Increased platelet serotonin in bipolar depression and hypomania. J Neural Transm 42:55-62

Young LT, Warsh JJ, Warsh JJ, Kish SJ, Shannak K, Hornykeiwicz O (1994): Reduced brain 5-HT and elevated NE turnover and metabolites in bipolar affective disorder. Biol Psychiatry 35:121-127

Young RC, Biggs JT, Ziegler VE, Meyer DA (1978): A rating scale for mania: reliability, validity and sensitivity. Br J Psychiatry 133:429-435

Young SN (1991): Some effects of dietary components (amino acids, carbohydrate, folic acid) on brain serotonin synthesis, mood, and behavior. Can J Physiol Pharmacol 69:893-903

Young SN, Smith SE, Pihl RO, Ervin FR (1985): Tryptophan depletion causes a rapid lowering of mood in normal males. Psychopharmacology (Berl) 87:173-177 